\title{
Life Stressors and Cognitive Styles in Children
}

\author{
Sebastiano Santostefano*, $\mathrm{M}^{\mathrm{a}}$ Angeles Quiroga Estévez ${ }^{* * *}$, and Susan Rooney Santostefano* \\ * The Institute for Child and Adolescent Development, Inc. \\ ** Complutense University of Madrid
}

To explore the way that children's cognitive functioning relates to stressors they report experjencing in every day life, this study used the approach of cognitive control theory, which defines cognition as a set of mobile functions that, in serving adaptation, shift in their organization. Children $(N=93)$, ranging in age from 56 to 115 months, were administered individually the Ljfe Stressor Interview and several cognitive control tasks. Chitatren who reported being exposed to arguments and threatening gestures among adults made nore errors when focusing attention while distracted by stimuli concerning nurture. Children who reported being upset by shootings and fights had more difficulty remembering test information depicting two persons in a shoot-out. The results are discussed in terms of the potential value of an approach that integrates cognitive activity with personility. Key words: life stressors, cognitive styles, children, cognition-personality relationship

En este estudio se ha utilizado el enfoque de la teoria de los controles cognitivos para explorar cómo se relaciona el funcionamiento cognitivo de los niños con los factores estresantes de los que informan. Este enfoque define la cognición como un conjunto de funciones móviles que cambian en su organización, al servicio de la adaptación. Se evaluó individualmente a 93 niños y niñas de edades comprendidas entre 56 y 115 meses, utilizando el Life Stressor Interview y diversas tareas de control cognitivo. Los resultados obtenidos muestran que los niños que informan de haberse sentido afectados por discusiones y gestos amenazantes entre aduitos, cometen más errores mientras centran la atención ante estímulos relacionados con el nutrimento. Los niños que informan de haberse sentido afectados por disparos y peleas, tuvieron más dificuitad en recordar la información del estímulo que muestra dos personás en un tiroteo. Los resultados obtenidos se discuten en relación al valor que posee un enfoque que integra la actividad cognitiva y la personalidad.

Palabras clave: factores estresantes vitales, estilos cognitivos, niños, relación cognicionpersonalidad

Correspondence concerning this urticle should be addressed 10: Sehastiano Santostefano. Institute for Child and Adolescent Development. Inc. 169 Grove Street. Wellesley, MA 02482 (USA). Fax; +781 2376815. E-mail: icadss@worldnet,att.net 
Interest in the effects of childhood life stressors has intensified in the past two decades (Johnson, 1986; Pynoos, Steinberg, \& Goenjian, 1996). Typically, studics have identified distress symptoms children display following exposure to natural disasters (c.g., hurricanes), isolated violent cvents (e.g., a school-yard shooting), more protracted cataclysmic stressors such as riots (Farver \& Frosch, 1996), and stressors created by war zones in foreign countries (Garbarino \& Kostelny, 1996; Matcksoud \& Aber, 1996). Moreover, studies of the effects of stressors on children typically segregate (rather than integrate) "cognitive effects" from "affective effects" (Armsworth \& Holaday, 1993). Yet, some authors (e.g., Edgcumbe \& Gavshon, 1985; GalatzerLevy. 1994; Johnson, 1986; Pynoos, et. al.. 1996) have argued that the stressors a child experiences cannot be defined objectively by others. These same authors have emphasized the nced to consider conscious and unconscious meanings/emotions evoked in children by various events. This point of view, for example, questions whether an cvent, such as a hurricane, would be construcd in the same way by all children.

To address these needs, the study followed cognitive control theory (Santostefano, 1978, 1985, 1998) that emerged from the "Now Look" approach to cognition, which was launched by three symposia convened between 1948 and 1955 (Sancostetano, 1991). The New Look provides an approach that atcmpts to integrate cognitive and emotional effects by embedding meanings/emotions within cognitive stimuli, on the one hand, and, on the other, that gives priority to what children interpret as stressful. This approach emphasized that individual differences in cognitive activity represented mental functions which operate outside of awareness, and which equilibrate and coordinate the calls for action from environmental stimuli (as interpreted by an individual) with the calls for action from the individual's personal, unconscious motives and emotions.

George Klein (1951, 1954; Klein \& Schlesinger, 1949). one of the leading figures of the New Look, reported data supporting the conceptualization that adults use cognitive functions to approach, avoid, select, and cluster information in order to coordinate information from the enviromment with information from the personal world of needs and meanings. He also proposed that the organizations of cognitive functions change in response to changes in stimulation, which evoke different meanings/emotions, in order to remain in adaptive control of information presented by a task, on the one hand, and, on the other, emotions and meanings evoked by the information as construed. Klein conceptualized these particular cognitive functions as "cognitive controls." (For a review of research supporting these proposals, see Santostefano, 1978, 1998; Wolitsky \& Wachtel, 1973).

Whereas Klein and his colleagues studied adults, Santostefano and his colleagues studied cognitive controls with normal and clinical populations of children (as well as adults) and extended Klein's formulations along several lines. We were interested in assessing whether individual differences in cognitive functioning reflected the way a child coordinates demands of environmental stimuli he or she experiences with the demands of the child's unconscious meanings and emotions. And we assumed the related position of the New Look, that the best way to study the way that a child's cognition maintains adaptive equilibrium between internal and external stimulation is to observe the child in various natural habitats. For examtele, we evaluated children at home and again while they were either in a hospital bed about 10 undergo surgery, or in a dentist chair about to undergo dental work (Shapiro, 1972; also repotted in Santostefano, 1978). Also, we evaluated young adults (who were learning to parachule) when they were in their homes, and again when at the airport preparing to perform their first parachute jump (Guthrie, 1967; also reported in Santostefano, 1978 ). In each of these studies, the organization of cognitive controls shifted when evaluated in one environment and then in another (e.g., home and hospital). The direction of the shift appeared to serve successful adaptation to the environment in question, a finding we claborite below.

But, as clinicians, we have been aware that practitioners typically cannot evaluate clients by assessing them in their homes, or in a hospital bed, or whatever the natural habitat might be. which Frenkl-Brunswick (1951) argucd were the best locations in which one could capture the way people cognitively construct a dynamic equilibrium between their personal world and environments. Typically, ats White (1991) pointed out, the environment within which most workers engage a child is no larger than a tabletop, and he urged workers to find ways of moving beyond this habitat.

in our attempt to remain allied with the goal of assessing children in different habtats, while simultaneously accepting the constraints of engaging children in the environment of a tabletop, we have been exploring ways of transforming the tabletop into natural habitats by presenting tasks to children that evoke different meanings/emotions, as well as requiring a particular cognitive mechanism. For cxample, to assess the way a child surveys information (the cognitive control tetmed focal antention) in different enviroments, representing different meaning/emotions, we ask children to scan different stimuli: in one trial, the child surveys dozens of geometric shapes (a neutral or relatively meaningless environment) randomly arrayed on a large sheet of paper and marks only circles and crosses, as quickly as possible. In another trial, the child surveys randomly arrayed pictures of cveryday objects such as clocks, shoes, chairs, telephones (personal meanings/emotions about everyday cvents). In another trial, the child surveys randomly atrayed picures of food-related objects such as a bottle of milk, a spoon, a loaf of breald (meaning/emotions concerning nurture). And in another trial, the child surveys randomly arrayed pictures of weapons such as a pistol, knife, arrow, sword (meanings/emotions conceming aggression). By comparing the vigor and breath 
of scanning a child displays with each of these environments, one has the opportunity to evaluate, for example, whether or not aggressive children scan more broadly and actively when surveying weapons and more narrowly and passively when surveying food-related items. And one has the opportunity to explore whether these shifts in scanning, in response to different environments, serve or interfere with adaptation and learning.

Following this approach, Santostefano $(1978,1998)$ identified five cognitive control processes in children: (a) body ego-tempo regulation: the manner in which a child constructs images representing the body-self and uses these images to regulate body motility; (b) focal attention: the manner in which a child scans fields of information; (c) field articulation: the manner in which a child selectively attends to information relevant to some conscious or unconscious intention, while actively withholding attention from information irrclevant to this intention; (d) levelingsharpening: the manner in which a child constructs and conserves iconic memory images of information and compares them to present perceptions; and (e) equivalence range: the manner in which a child categorizes and conceptualizes information. Studies supported the construct validity and reliability of the stimuli and test methods used to assess each of these controls, and also showed that each cognitive control process follows a developmental course, from cognitive organizations that characterize early development to those characterizing later development. Moreover, studies showed that whereas these cognitive mechanisms changed with age and cognitive maturity, they were not consistently related to sex or IQ (e.g., Clark, 1992; Santostefano, 1978, 1986, 1988, 1995, 1998; Santostefano \& Paley, 1964; Santostefano \& Rieder, 1984; Wertlicb, 1979).

With normed data defining the developmental levels of each cognitive control (Santostcfano, 1988), we investigated whether or not a shift in cognitive control functioning toward developmentally carlier (i.e., regression) or toward more mature levels (progression) was adaptive or maladaptive when coping with a particular, evocative environment.

For example, in a study mentioned earlier, (Santostefano, 1978; Shapiro, 1972), lests of leveling-sharpening were administered 10 children when at home and again in a hospital room before undergoing surgery. Their test performance was compared with that of controls (children evaluated at home and again at the dental office, and children evaluated at home on two occasions). The surgical group showed the greatest shift towards a more immature organization of this control (i.e., they leveled information) when in the hospital environment versus the home environment. Of particular importance, the children who shifted most towards leveling external information when in the hospital were rated by their mothers as better adjusted post-opcratively. In this instance, a regressive shift in a cognitive control was associated with successful adaptation. In contrast, students assessed in their dorms and again in a classroom before taking an examination, and college students assessed at home and again at the airport before executing a parachute jump, shifted significantly toward sharpening information (comparing and relating past, external information with present perceptions). In these environments, a progressive shift in organization served adaptation (Guthrie, 1967; Santostefano, 1978).

In considering these results, we should recall the levelingsharpening cognitive control process. The cognitive mechanism of leveling-sharpening concerns the degree to which past information, with its emotions and meanings, is integrated within and related to one's perceptions of present stimulation. In addition, when external information is leveled, cognition shifts away from external information, becomes "intemally oriented," and focuses on emotions and meanings. And when external information is sharpened, cognition becomes "externally oriented" and shifts away from inner emotions, fantasies, and meanings. If we apply this formulation to the children who were facing surgery, they avoided (leveled) external information, about which they could do nothing, and locused on inner emotions and fantasies, a shift that resulted in more successful adaptation. Similarly, if we apply this formulation to the young adults about to execute a parachuce jump, shifting toward sharpening external information and avoiding inner emotions, anxieties, and meanings served successful adaptation.

The mobility of cognitive controls, and the regressive and progressive shifts that occur in response to different stimulation, reflect a process of "cognitive-affective balance" (Santostefano, 1978; Santostefano \& Rieder, 1984). In this process, in order to maintain a balance between meanings/emotions and external stimulation, cognitive controls shift regressively or progressively to immature or mature levels of functioning in the service of adaptation.

These concepts and methods have proven useful in studies of a wide range of clinically relevant issues. For example, unique organizations of cognitive control functioning have been identified as related to: reading disabilities (Cotugno, 1981); learning disabilities in South African children (Engelbrecht, 1993); hyperactive children (Cotugno, 1987); maltreated children (Rieder \& Cicchetti, 1989; Rogosch, Cicchetij, \& Aber, 1995); aggressive children (Santostefano \& Rieder, 1984; Wertlieb, 1979); violent juvenile inpatients (Calicchia, Moncata, \& Santostefano, 1993); predicting physically aggressive behavior (Santostefano \& Moncata, 1989); being orphaned (Santostefano, 1978); living in a bilingual home (E. Geva, 1976, personal communication); and Alzheimer's disease in adults (Foldi, Jutagir, Davidoff, \& Gould, 1992). In addition, changes in cognitive control functioning have been identified in five- and six-year old chitdren who were coping with the transition of entering school (Quiroga, López, Gómez, Fennández de lá Vega, \& Pérez, 1998), and in 14- and 15-year old children who were coping with the transition from elementary school to high school (Quiroga, Rodríguez, et, al, 1998). 
As outlined above, numerous studics have supported two interrelated assumptions that form the foundation of cognitive control theory that emerged from the New Look in perception and personality: (a) particular cognitive functions (cognitive controls) change in organization in response to stimuli that arouse conscious and unconscious meanings and emotions (unique to the individual's life experiences and interpretation of the stimulation) in order to coordinate the demands of the stimulation with the demands of associated meanings/emotions: and (b) individual differences in regressive and progressive shifts in these cognitive functions relate to a person's unique way of coping with and fearnitrg from the envirommental situation in question. Searching for other opportunities to explore the heuristic value of these assumptions and the New Look approach to cognition and enotion, we set out to observe whether or not changes in cognitive functioning that occu in response to different test stimuli relate to stressful events children report having experienced.

The aim of the study reported here. then, was to explore whether changes in the organization of two of the cognitive controls noted carlier (field articulation and levelingsharpening), occarring in response to test stimuli cvoking different emotions, (aggression or affiliation/nurture) that may be associated with stresslul events chillen experience, are related to whether or not children reported witnessing shooting/fights, verbal arguments/threatening gestures among adults, or death of a loved-one. Although previous findings were not available concerning the relations between lifestressors children define and changes in their cognitive functioning. we hypothesized that children who reported being upset by shootings/fights would be more distracted by pictures that evoke aggressive meanings and would remember fewer details of a scene depicting interpersonal aggression. We also hypothesized that children who reported arguments among adults and death of a loved-one would be more distracted by pictures that evoke meanings of nutture and would remember more details of a scene depicting interpersonal friendships.

\section{Method}

\section{Participant:}

The children studied were altending an inner-cily school serving a low, sociceconomic population. During two successive years, all kindergarten children were evaluated, with parental consent, at school during the school day. In addition, 15 children attending the $1^{\text {st }}$ or $2^{\text {nd }}$ grades, who were referrod by tcachers, were also evaluated. Children who presented learning and adjustment problems were not included in this study, resulting in a total group of 93 children $(80$ kindergarten and 13 lirstand second-graders; 39 females and 54 males; 37 African Americans, 51 Latinos, 4 Caucasians, and 1 Asian). Ages ranged from 56 to 115 months, $M=79$ months, $S D=15.96$, median age $=76$ months, mode $=72$ months.

\section{Materials}

Life Stressor Interview (Santostefano, 1992b). After surficient rapport was established, a child was asked, "Tell me whether anylhing has happened that upset you al lot?" Whenever indicaled, the examiner helped the child elaborate her or his responses with non-directive questions. As an example, a child responded. "My grandpa died." The examiner asked, "Is there anything else you can tell me about that?" The child responded, "He was drinking bect; his lriend said "get some beer in the car"; when he came back, the friend shot him." Some children reported more than one stressor spontancously. If a child reported only one stressor, the examiner asked only once, "Is there anything else that upsets you a lot?"

Two raters independently rated each response and agreed $95 \%$ of the time. Disagreements were negotiated in group discussions.

Frut Distraction Test (FDT; Santostefano. 1978, 1988). Ihe HDl evaluates the way a child attends selectively to relevant information while trying to jgnore information irrelevant to the task at hand, a cognitive control termed field articulation. Age norms are available as well as studies supporting test-retest reliability (Santostefano, 1978, 1986, 1988, 1998). For example, in one study (Santostelano, 1978, 1988). 5 [ children were administered the FDT at the start of kindergarten and again at the start of $2^{\text {nd }}, 4^{\text {th }}$, and $5^{\text {th }}$ grades. Correlations reached statistical signilicance for the most part, anging from 29 to .74, with higher correlations observed for test-retests obtained in adjacent years than when testing was separated by two years or more.

Initially, the child was given Card I. consisting of colored bars (red, yellow, green, bluc), and trained to name the colors as quickly as possible. (Children had been previously screened for color perception with the Dvorine Isochromatic Plates.) Then, the child was administered Card II, on which were randonly arrayed 50 colored pictures of three firuits and one vegetable, arranged in ten rows, tive items in cach row (c.g., yellow banama, red apple, blue grapes, green lettuce). The child was asked to name the colors as quickly as possible and to ignore the fruits. Card III was exactly the salme as Cald Il except that pictures of six food-related objects (e.g. bottle of milk, Joaf of bread, ice cream cone) and six nonfoodrelated objects (e.g. car, clock) were printed along sicle the colored fruit. The child was asked to try to ignore the pictures and name the colors again as rapidly as possible. Rescarch supports the view that performance with this card assesses a child's ability to selectively attend while meanings/emotions concerning food/nurture are aroused. For example, in one study (Santostetano, 1978), orphaned children took longer to name the colors of Card II I (mean difference of Card III Card II = 20 seconds), brain-damaged children wore delaycd less (mean difference Card III - Cand II $=10$ seconds), and public schoot children the least (mean difference Card III Card $I I=4$ seconds $), F(2,123)=3.16, p=05$. The orphaned 
children also made the most reading errors and the public school children the least. In addition, after Card III was removed, each child was asked to recall the peripherat pictures she or he happened to notice. The orphaned children recalled more objects overall and more of the food-related objects, suggesting that being orphancd is associated with overincluding information that is irrelevant to the task at band, especially information that evokes the need for nurture.

Card IV presented the same fruits and vegetable, in the same locations as Card II, but now each was colored incorrectly (e.g., a banana was colored red, blue, or green but never yellow). The child was asked to try to ignore the colors and name as rapicly as possible the correct color of each item displayed. Research supports the view that performance with this card measures a child's ability to selectively attend while dealing with contradictions and cognitive conflict. For example, in a study by Tarembo (cited in Santostefano, 1978), children whose performance ot the Matching Familiar Figures Test showed extreme cognitive impulsivity took significantly longer to name the colors and made more reading errors on Card IV versus Card II when compared with children who were not cognitively impulsive. E. Geva (1976, personal communication), hypothesizing that the experience of growing up in a bilingual home cultivates the ability to deal with contradiction (now one language is relevant, now the other), found that children who lived in bilingual homes named the correct colors for Card IV more quickly than the children who lived in homes where only one language was spoken.

Card V presented the items colored correctly, in the same sequence as Card III, but now, pictures of weapons (c.g., pistol, rifle, sword) surrounded the fruit. Research supports the view that performance with this card assesses a child's ability to selectively altend while meanings/emotions concerning aggression are aroused. Inpatient children who were rated as physically aggressive by their teachers named the colors of Card $V$ more quickly than did less aggressive children (Santostefano \& Rieder, 1984: Calicchia, Moncata, \& Santostefano, 1993).

Time in seconds required to name the colors, and naming errors, were recorded for each card. For each child, Card III reading lime and naming errors were compared with those of Card V, reflecting whether the child was distracted more by stimuli arousing emotions concerning food/nurture versus aggression. And for each child, Card II reading time and naming errors were compared with those of Card IV, reflecting whether the child was distracted by contradictions.

In addition, two types of naming errors were calculated: (a) total errors-the number of naming errors made with each card, and (b) bursts of errors-the number of times a child made two or more naming errors in stccession while naming the colors of three (or fewer) consecutive items. Errors are conceptualized as reflecting slips of cognition or cognitive conflict, and a momentary loss of cognitive-affective balance, between the demands of stimuli and the demands of associated meanings/emotions. Bursts of crrors are conceptualized as reflecting more extreme conflict (see Santostefano \& Moncata, 1989; Santostefano \& Rieder, 1994, for supporting data).

Loveling-Sharpening Shoot-Out Test (LSSOT) and Leveling-Sharpening Friends Test (LSFT; Santostefano, 1992a, 1995, 1998). "The LSSOT and LSFI" assess the manner in which a child maintains in memory visual images of information and compares these images to perceptions of on-going information, a cognitive control termed levelingsharpening. The LSSOT and LSFT are identical in make up, procedure, and task requirement. With each, 63 pictures of a scene $(81 / 2 \times 11$ inches) are displayed in succession, five seconds cach display. Gradually, throughout the series, 20 details are omilled accumulatively from the scene. The child is asked to report changes noticed in the scene.

The LSSOT consists of a scene of two cowboys in a shoot-out. The one being shot is located in the center of the scene, lacing the viewer: he is slumping over, pistol falling from his hand, and blood spots covering his shitt. We refer to this figure as the "victim." The other cowboy is located to the left of the scene, with his back to the viewer, so that one sees only his profile and the pistol he is firing. The LSFI' consists of two cowboys greeting each other. The cowboy extending a greeting is smiling and faces the viewer. We refer to this figure as the "fricnd." The other cowboy is located to the left of the scene, with his back to the viewer, so that only his profile is seen.

Age norms are available as well as studies supporting reliability and construct validity (e.g., Calicchia, Moncata, \& Santostefano, 1993; Clark, 1992; Santostefano, 1986, 1995; Sintostefano \& Rieder, 1984). For example, in one study (Santostefano \& Rieder, 1984), hospitalized children who were more aggressive perceived more changes and produced fewer errors with the aggressive scene than with a nonaggressive scenc. In another study (Santostefano \& Moncata, 1989), a group of atolescents housed in a detention center because of violence sharpened (perceived more changes sooner) with the ISSOT, suggesting concordance between their aggressive fantasies and the meaning of the aggressive test stimuli. In contrast, outpatient and public school children leveled more with the LSSOT (perceived rewer changes), suggesting discordance between their aggressive fantasies and the meaning of the aggressive test scene.

As for reliability, for example, in an on-going study (Quiroga \& Santostefano, 1999), 40 Latino and AfricanAmerican children attending public school in the United Statcs were administered the LSSOT and LSFT in kindergarten and again in $1^{\text {st }}$ grade. Their performance with each procedure was very consistent over the period of 12 14 months: I SSSOT correct tatio score, Kindergarten $\times 1^{\text {st }}$ grade, $r=.50, p=.002$; LSFT correct ratio score, Kindergarten $\times 1^{\mathrm{st}}$ grade, $r=.39, p=.02$. The same consistency was observed over a two-year period with a group of 36 children attending public school in Spain who were administered the LSSOT and LSFT' in I It $^{\text {grade }}$ and 
again in $2^{\text {nd }}$ and $3^{\text {ril }}$ grades: LSSOT correct ratio scores, $1^{\text {st }}$ grade $\times 2^{\text {nd }}$ grade, $r=48, p=05 ; 1^{\text {st }}$ grade $\times 3$ rd grade, $r=.52, p=.05 ; 2^{\text {nd }}$ grade $\times 3^{\text {rd }}$ grade, $r=.62, p=.05$; LSFT correct ratio scores, $1^{\text {st }}$ grade $\times 2^{\text {nd }}$ grade, $r=.19$, $p=$ nonsignificant; $1^{\text {st }}$ grade $\times 3$. $r$ grade, $r=.56, p=.01$; and $2^{\text {nd }}$ grade $\times 3^{\text {rd }}$ grade, $r=.67, p=.01$.

Performance was evaluated with three scores: (a) correct change ratio: the number of correct changes detected and how soon a change was perceived once it was introduced (i.e., the number of scenes displayed before a change was perceived) The greater the number of changes detected, and the sooner changes were detected, the smaller the ratio (cognitive sharpening). Numerically small ratios indicate a child holds a differentiated image in memory of the pattern of on-going information. The fewer the changes noticed, and the greater the lag before a change is noticed, the larger the ratio (cognitive leveling). Numerically larger ratios indicate a child holds a global image in memory of the pattern of on-going information. (h) Incorrect change score: the total number of changes reported that in fact do not occur (e.g., the sun is perceived as shifting location when it does not; blood stains on the shirt of the cowboy are perceived as having increased, when this does not occur); and (c) friend and victim scores: of the 20 changes introduced throughoun the series, four occur on the person of the friend in the LSFT (culf lines of shirt; shirr pocket located on the upper right hand side of the chest area; shirt flap, buttons and collar; coil of rope in his right hand); four changes occur on the person of the victim of the LSSOT (cuff lines of shirt; blood splotches located on the upper right side of the chest area of his shirt; shirt flap, buttons and collar; pistol in his right hand).

For each stressor group, LSSOT correct ratio scores, incorrect change scores, and victim scores were compared with their counterparts in the LSFT.

\section{Procedure}

In individual sessions, cach child was administered the Life Stressor Interview during the first meeting. and three tests of cognitive controls during two subsequent meetings scheduled within five school days. The sequence of the cognitive tests was randomized (Fruit Distraction Test, Leveling-Sharponing Friends Test, Leveling-Sharpening Shoot-Out Test).

\section{Statistical Analyses}

Each type of stressor reported was coded as a dummy variable. For each task and each dependent variable, we analyzed the effect of the three dummy variables through regression analyses. If regression analyses results showed a statistically signilicant effect $(\mathrm{p}<.016)$, we performed ANOVA as a second step, using an alpha level of .016 or 025, depending on the number of comparisons being made, following the Bonferroni correction. Effect size and power indexes of the contrasts were calculated with the Statistical Power Analysis by Borenstein \& Cohen (1988) and taken into account for conclusions.

\section{Results}

For the purpose of this exploratory study, children were selected who reported one to three stressful events and placed into one of three groups: (a) those who reported being upset by witnessing shootings and physical fights $(n=47)$, (b) those who reported being upset by arguments and threatening gestures between ildults $(n=49)$, and (c) those who reported being upset by the death of a loved-one $(n=29)$. These stressors were selected becituse the number of children reporting them permitted statistical analyses.

For the most part, children who reported any one of the three stressors selected for this study did not tend to report the others. Correlations among these stressors were: a) Shooling/Fights $\times$ Arguments/ Threatening Gestures, $r=018$ : b) Death of a Loved-One $\times$ Shooting/Fights, $r=.03$; and c) Death of a Loved-One $\times$ Arguments/Threatening Gestures, $r=-.11$. These low correlation values indicate that the stressor variables are independent. In fact, of the total group, eight children reported both shootings/fights and death of a loved-one, but they did not report arguments/threatening gestures. Six children reported both arguments/threatening gestures and death of a loved-one, but they did not report shootings/lights. Two children reported events that qualified for each of the three catcgories we studied (shootings/fights, arguments/threatening gestures, and death of a loved-one). Therefore, eight children were members of both the shootings/fights stressor group and the death of a loved-one group, six children were members of both the arguments group and death of a loved-one group, and two children were members of each of the three groups. On the one hand, we assume the constructivist position that if a child's subjective world construes as upsetting both arguments and death of a loved-one, for example, that child's personal world should participate within each group whose members have reported these events. On the other hand, we also acknowledge that if a child's subjective world construes more than one type of event as upsething, this child's inner world is characterized by a particular pattern of stressors. We did not have sufficient numbers of children to study patterns of stressors, an issue we consider in the discussion.

The cognitive test performance of children who reported the stressor in question was compared with the perfomance of children who did not report that stressor; that is, each comparison was conducted with a dichotomous variable: children who reported a stressor versus children who did not report that stressor.

To begin, we explored whether differences in our independem and dependent variables were associated with sex and race. 
$\operatorname{Sex}$

No statistically significant difference was observed in total number of stressors reported by females and males. Each group reported a mean number of about 3.6 stressors. Chisquare analyses were conducted comparing sex with reporting versus not reporting shootings/fights, arguments, and death of a loved-one. Sex was also entered into two-way analyses of variance with scores on each of the cognitive test dependent variables: time and errors with FDT Cards III versus V and Cards II versus IV; ISFT versus LSSOT correct change ratios, incorrect change scores, and friend versus victim scores. No statistically significant differences were observed.

Race

To assess the variable race, we compared only Latino and African-American children because only four Caucasians and one Asian were members of our group. When chi-square analyses compared race and types of stressors (reporting vs. not reporting shooting/fights, arguments, death of a lovedone), no statistically significant differences were observed.

The race variable was also entered into separate, two-way analyses of variance with each set of cognitive dependent variables. No statistically significant differences were observed.

\section{Selectively Attending in the Face of Distractions and} Contradictions (The Field Articulation Cognitive Control)

Children were grouped in terms of whether or not they reported each of the three stressors and compared through regression analysis, in terms of time required, and errors and bursts of errors made when naming the colors of fruit on Cards Ill (food-related distractions) versus V (weapons as distractions).

Results from the regression analysis showed only a statistically significant function for Card III versus Card $V$ in bursts of errors. For this variable, reporting arguments/threatening gestures as a life stressor produced a statistically significant effect, $F(1,91)=7.512, p=.007$.

ANOVA results showed a statistically significant interaction effect, $F(1,91)=7.32, p=.008$, size effect $=$ .33 , power $=.77$, for arguments/threatening gestures on Card III versus Card V in bursts of errors. As shown in Figure 1 , the errors produced by children who reported arguments/threatening gestures occurred in bursts more often when faced with food-related distractions than with pictures of weapons. Children who reported arguments produced more bursts of errors with Card 111 ( $M=1.49$ bursts, $S D=1.9$ ) than with Card $\vee(M=0.67$ bursts, $S D=1.3)$. Children who did not report this stressor tended to produce about the same number of bursts of errors in each condition (Card III $M=0.67$ bursts, $S D=1.4$; Card $\vee M=0.63$ bursts, $S D=$ 1.1). The difference between groups in number of bursts produced in response to Card III was statistically significant, $t(91)=2.40, p=.02$. The groups produced nearly the same number of bursts of errors in response to Card V. This finding suggests that, of the stressors evaluated, arguments/threatening gestures was associated with disruptions in cognitive/affective balance as cognition coordinated the task requirements with meanings/emotions concerning food/nurture.

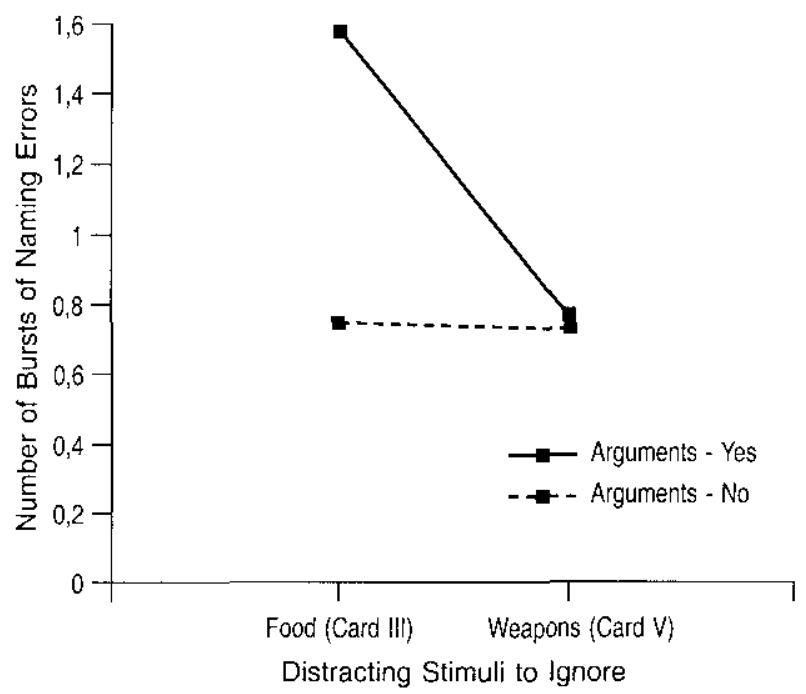

Figure 1. Reporting arguments/threatening gestures and bursts of errors made while distracted by pictures of food and weapons (FDT III vs. V).

Holding Information in Memory (The LevelingSharpening Cognitive Control)

Results from the regression analysis showed a statistically significant function for the LSSOT versus LSFT correct change ratio. For this variable, reporting shootings/fights as a life stressor produced a statistically significant effect, $F(1,91)=6.53, p=.012$.

ANOVA results showed a statistically significant interaction elfect, $F(1,91)=5.78, p=.01$, size effect $=.33$, power $=.707$, lor shootings/fights on LSSOT versus LSFT in correct change ratio (see Figure 2, left graph). Children who reported shootings/fights detected fewer changes and later (cognitive leveling) with the shoot-out scene (LSSOT correct ratio $M=23.5, S D=4.1$ ) versus the riendship scene ( $\mathrm{LSFT}$ conrect ratio $M=22.2, S D=4.6$ ). In contrast, children who did not report this stressor delected more changes and sooner (cognitive sharpening) with the shoot-out scene (LSSOT correct ratio $M=21.8, S D=3.5$ ) than with the friendship scene (LSFT conrect ratio $M=23.7, S D=4.1$ ). The difference between the groups in remembering details of the shoot-out scene was not statistically significant, $t(91)$ $=1.37, p=.12$. Nor was the difference in their remembering details of the friendship scene, $r(91)=1.14, p=.15$. However, as noled, the interaction between test stimuli and reporting shootings/fights was statistically significant. 


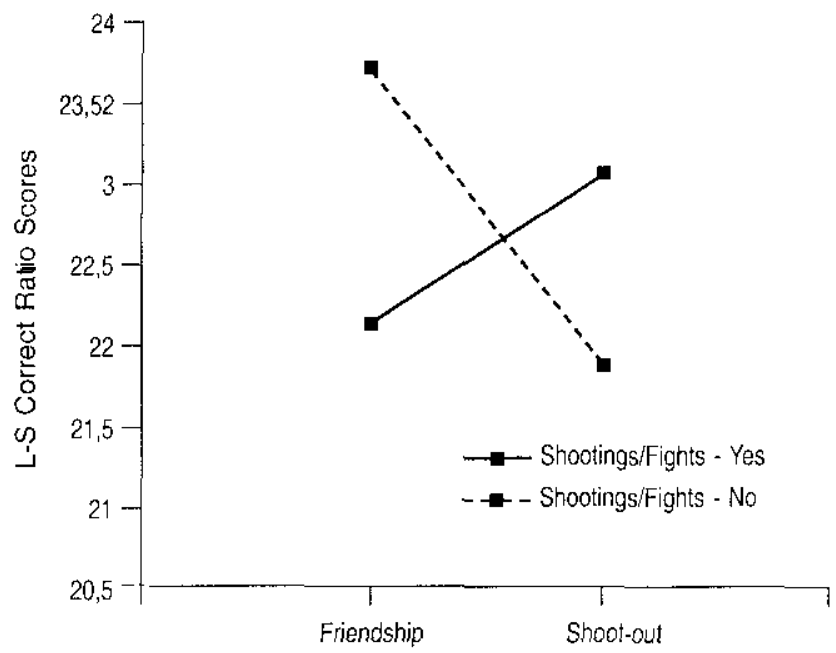

Test Scenes Remembered

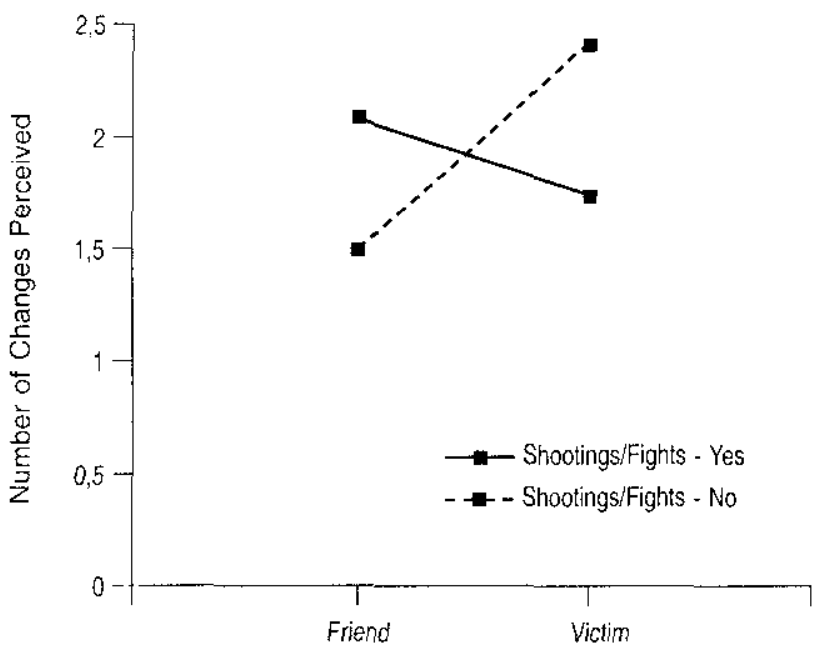

Details of Human Figures Remembered

Figure 2. Reporting shootings/tights and remembering details of pictures depicting a friendship and shool-out and details on the persons of a friend and a vicrim (LSFT vs. LSSOT).

In addition, regression analysis showed a statistically significant effect for shootings/lights on the changes reported that occurred on the ligure of the victim versus the figure of friend, $F(1,91)=11.908, p=.001$.

ANOVA results showed a statistically significant interaction effect, $F(1,91)=13.18, p=.001$, size effect $=$ .33 , power $=.89$, for reporting shootings/ijghts on LSSOT victim versus LSFT friend scores. As shown in Figure 2. right graph. children who reported this stressor detected fewer changes that occurred on the person of the victim $(M=1.8$, $S D=1.3)$ than on the person of the friend $(M=2.1, S D=$ 1.1). Children who did not report shootings/fights detected more changes on the person of the victim $(M=2.3, S D=$ 0.8 ) than on the person of the friend $(M=1.5, S D=0.9)$ The difference between groups in the number of changes perceived on the person of the vietim was not statistically signilicant, $t(91)=1.04, p=.20$. The difference between groups in the number of changes perceived on the person of the fricnd was statisticaliy significant, $t(91)=2.69 . p=.001$.

\section{Discussion}

To explore the relation between cognition and emotion in young children, we employed a theory that defines cognition as a set of mobile functions or processes (cognitive controls), which shift in their organizations as they respond to and coordinate requirements of external stimuli, as construed, on the one hand. and the requirements of personal meanings/emotions evoked by the stimuki, on the other. With this theory as a guide, we employed two interrelated methods. With one, we leumed from inner-city children what they experieneed as stressful events. Our Life-Stressor
Interview converges with Janoff-Bulman's (1995) proposal that stressors that produce anxiety or negative cmotions are connected with a chitl's unique system of symbolizing and representing. With the other meihod, we observed whether the cognitive controls of these inner-city children changed in organization when coordinating task requirements with two types of stimuli evoking different meanings/cmotions: either nurture/affiliation or iggression.

With one task, children werc asked to selectively attend to information designated as relevant (the colors of pictures of fruit), while simultaneously responding to and coordinating information irrelcvant to this intention (meanings/emotions aroused by piclures of food-related items and weapons, and colors that contradicted the colors that should be there). With the other task. children were asked to hold information in memory while simultaneously responding to and coordinating meanings/cmotions evoked by two scenes (one cowboy shooting another and one cowboy greeting another).

Of the stressful events studied is indejendent variables (shootings/lights, arguments/hreatening gestures, death of a loved-one), children who reported one of these stressors, for the most part, tended not to report the others. Only 16 chiklren (17\%) reported more than one type of stressful event (14 children reponted two of the types, and two reported ill three). The issue of children reporting two or more stressors relates to an intriguing direction for future research. Following the constructivist viewpoint, we propose that if a child reports two or more stressors, these stressors form a pattern that represents the unique meaning a child assigns to experiences with others and to situations. Rather than viewing a child's reporting tive stressors versus two, for example. as indicating a higher level or degree of stress, we propose that multiple stressors define a more differentiated/integrated and complex 
Gestall of meanings. We also propose that an uncterstanding of the relationship between cognition and emotion would be entranced if we compared the cognitive control funclioning of children who reported, for example, events involving shootings/fights and death of a loved-one, with children who report events involving illness/hospitalization of a loved-one and death of a loved-one. As another example, one could compare the cognitive functioning of children who report both divorce and arguments among adults with children who report both divorce and illness/hospitalization of a loved-one.

When we related the cognitive control test performance of children who reported each of the stressors with the test performance of children who did not report that particular stressor, differences were observed in the way children who reported either shootings/lights or arguments among adults maintained cognitive-affective balance when managing tasks that evoked different meanings/emotions.

The way a child selectively attended to and balanced the demands of stimuli designated as releyant, and the demands of meanings/etnotions concerning nurture, related to the stressor of witnessing arguments among adults. Childten who reported arguments as a stressor produced more bursts of crors (experienced more disruptions in cognitive/aflective balance) while naming colors ol fruit surrounded by pictures of food items than while naming colors of fruits surrounded by pictures of weapons. Our finding suggests that witnessing arguments is associated with cognitive imbalance triggered by concerns and conflict about being fed and nurtured. This observation adds to one position in the literature proposing that children who experience stress "may experience intolerable. intrusive thoughts and images" (Armsworth \& Holaday, 1993, p.50). In our study, the stress of witnessing arguments was associated with intrusive thoughts and images that concern nurture, suggesting directions for future research: that test methods be devised which explore whether other types of intrusive thoughts and images arc associated with witnessing arguments as well as with other stressors.

Leveling-sharpening cognitive control functioning (holding images of information in memory over time) related to the stress of witnessing shootings/fights. Children who reported shootings/fights porceived lewer changes and later in the shootout scene and more changes and sooner in the friendship scene. This result suggests that children who reported being upset by shootings and fights maintain a form of cognitive-affective balance with the leveling-sharpening mechanism that appears to avoid (level) external stimulation that arouses aggressive meanings/emotions, so that past information (with its aggressive emotions and meanings) is not integtated within the child's perceptions of present stimulation. One possible psychodynamic interpretation of this difference is that these children construe fights and shootings as especially meaningful for a variety of reasons; e.g., they are coping with conflicts concerning their own aggression. Therefore, when construing the shoot-out scene and the victim, these children unconsciously experienced fear and anxiety and therefore avoided engaging this stimulus (i.c., denied/suppressed/repressed). In addition, that children who reported shootings-lights also encoded fewer details on the person of the victim and more on the person of the fricnd relates to the view proposed decades ago by the Now Look approach to perception (see above), that cognitive activity could take place outside of awareness when balancing and coordinating information and emotions in ways that serve a child's unique adaptive intentions and personal world. It seems likely that these children were not aware of the fact that they selectively encoded fewer or more details located on the person being shot or on the person extending a grceting.

Our results with the leveling-sharpening cognitive control also relate to reports that traumatized children show "memory impairments" (Armsworth \& Holaday, 1993, p. 50). We observed that children who reported shootings/fights as a stressor remembered fewer details of a scene of two persons in a shoot-out and fewer details located on the person being shot, but more details of a scene representing friestship and more details located on the person extending a greeting. Because we used tests that presented different stimuli to be remembered, our observation suggests "selective memory impairment" rather than an "overall memory impairment," Again, a direction for future research is suggested: that studies of memory impairment due to stressors make use of different test stimuli to be remembered that cvoke different types of moanings/cmotions.

Our results converge with the proposal (Pynoos, Steinberg, \& Goenjian, 1996) that investigators consider conscious and unconscious meanings/emotions evoked by various stressors and explore several forms of childhood stressors simultaneously rather than study the effects of each independently.

Our results also echo the necd, introduced by the New Look approach, that methods be devised to assess cognition with tasks that allow a person to experience personal meanings and emotions, in addition to IQ tests, questionnaires, and rating scales, that seem to be preferred in studies relating cognition to stressors (e.g., Armsworth \& Holaday, 1993; Lutgendorf, Antoni, \& Kumar, 1994: Van der Kolk \& Ducey, [989).

As Bruner (1992, p. 780) noted, when he recently reflected upon his participation in the New Look movement, "... we early warriors of the first New Look were going to rid psychology of the 'pure percept.' Indeed, it was a constructivist view of perception (which) gave the first New Look a strong instrumentalist bias: perception was seen as an instrument of adaptation subserving fundamental adaptive functions."

Klein (1970) urged clinicians and investigators to jemove the boundary that typically segregates cognition and emotion. Borrowing Freud's (1923/1961) metaphor of emotion (drive) as a galloping horse and cognition (ego) as a rider attempting to control the horse, some investigators have focused on the horse, more or less ignoring the rider. Others have focused on the rider, more or less ignoring the horse. We also propose that when exploring the relation between cognition and emotion, the horse and rider should be studied as one. 


\section{References}

Armsworth, M.W., \& Holaday, M. (1993). The effects of psychological tratuma on children and adolescents. Jowmal of Commeling and Development. 72, 49-56.

Borenstein, M., \& Cohen. J. (1988). Statisfical power analysix: A computer program. Hillsdale, NJ; Erthaum.

Braner. J.S. (1992). Another look at New Look I. American Psychologist, 47, 780-783

Calicchia, J.A., Moncata, S.J.. \& Santostefano, S. (1993). Cognitive control differences in violent juvenile inpatients. Joumal of Clinical Psychology, 49, 731-740.

Clark, M.F. (1992). A developmental assessment of the cognitive princinal of leveling-sharpening in two interpersomat-emotional contexts: Aggression and affiliation. Unpublished doctoral dissertation, Boston College, Boston, MA.

Colugno, A.l. (1981). Cognitive controls and reading disabilities revisitcd. Psychology in the Schools, 18. 455-458.

Cotugno, A.J. (1987). Cognitive control functioning in hyperactive and nonhyperactive children. Jonmal of Leaning Disabilities, 20,563-567

Edgcumbe. R.S., \& Gaushon, A. (1985). Clinical comparisons of traumatic events and reactions. Bulletint of the Anna Freud Center, 8, 3-21.

Engelbrecht, P. (1993). A South African perspective on cognitive control therapy for learning disabled children. School Psychology intemational, 14, 111-117.

Farver, J.M., \& Frosch, D.L. (1996). L.A. stories: Aggression in preschoolers' spontaneous marratives after the riots of 1992 . Child Developmont, 67, 19-32.

Foldi, N.S., Jutagir, R., Davidoff, D., \& Gould. T. (1992). Selective attention skills in Alzhejmer disease. Joumal of Gerontology. 47, 147-153.

Frenkl-Brunswick, E. (195I). Personality theory and perception. In R. R. Blake \& G. V. Ramsey (Eds.), Perception: An approach fo persunality (pp. 356-420). New York: Ronald Press.

Freud, S. (1961). The ego and the id. In J. Strachey (Ed. and Trans.), The standard edition of the complete psychological works of Sigmund Freud (Vol. 19, pp. 3-66). London: Hogath Press. (Original work published 1923).

Galatzer-Levy, R.M. (1994). Children, had happenings and meanings. Joumal of the Amorican Psychoanalytic Association, 42, 997-1000.

Garbarino, J., \& Kostelny, K. (1996). The effects of political violence on Palestinim chidren's behavior probiems. Child Development, 67, 33-45.

Gruber, H.E., Hammond, K.R., \& Jessor, R. (Eds.). (1957). Contemporary approaches to cognition. Cambridge, MA: Harvard University Press.

Guthrie, G.D. (1967) Changes in cognitive functioning under stress: A study of plasticity in cognitive controls. Unpublished doctoral dissertation, Clark University, Worcester, MA.

Janoff-Bulman, R. (1995). Victims of violence. In G.S. Everly \& J.M. Lating (Eds.), Psychotraumatology. New York: Plenum Press.
Johnson, J.H. (1986). Life ewonts as streswors in childhood and adolescence. Newbury Park. NJ: Sage.

Klein, G.S. (1951). The personal world through perception. In R.R. Blake \& G.V. Ramsey (Eds.), Perception: An approath to personality (pp. 328-355). New York: Roniald Press.

Klein, G.S. (1954). Need and regulation. In M.R. Jones (Ed.). Nebraska symposiam on morivaton (Vol. 2. pp. 224-274). Lincoln: University of Nebraska Press.

Klein, G.S. (1970). Perception, motiles and persontality. New York: Knopf.

Klein. G.S., \& Schlesinger, H.J. (1949). Where is the perceiver in perceptual theory? Jotmal of Personalify, 18, 32-47

Lutgendorf, S.K. Antoni. M.H. \& Kumar, M. (1994). Changes in cognitive coping strategies predict EBV-antibody titer change following a stressor. Jommal of Pswchowomatic Researh, 38 , $63-78$.

Macksoud. M.S., \& Aber, J.L. (1996). The war experience and psychological development of childiren in Lebanon. Child Developmen, 67, 701-88.

Pynoos, R.S. Steinberg, A.M. \& Goenjian, A. (1996). Traumatic stress in childhood and adolescence: Recent developments and current controversies. In B.A. Van der Kolk, A.C. McFarlane. \& L. Weistellt (Eds.). Traumatic stress: The effects of overwhelming experience on mind, body, and society (pp. 33 [. 358). New York: Guilford Press.

Quiroga. M.A., López, V., Gómez, M.E., Fernández de la Vega. S., \& Pérez, F. (1998). Diferencias interindividuales en los perfies de desarrollo del estilo cognitivo al comenzar la escolaridad. In M.P. Sánchez López \& M.A. Quiroga (Eds.). Perspecinas actuales en la investigación psicológica de las diferencias indiriduales (pp. 434 440). Madrid: Editorial Centro de Estudios Ramón Areces.

Quiroga, M.A., Rodríguez, J., Nieto, R., Orozco, M., Salamanca, M., \& Murilo, MJ. (1998). Perfiles diferenciales de estilo cognitivo ante situaciones de cambio como explicación de las diferencias en rendimiento: el paso del Colegio al Instituto. In M.P. Sánchez Lóper \& M.A. Quiroga (Eds.), Perspecitas actuales en la investigación psicologica de las diferencias individuales (pp, 441-447). Madrid: Editomal Centro de Estudios Ramón Areces.

Quiroga. M.A.. \& Santostctano, S. (1999) Changes in fantasies of children concerning aggression and affiliation as reflected by the balance maintained between cognition and emotion over time. Unpublished manuscript.

Rieder, C., \& Cicchetti, D. (1989), Organizational perceptive on cognitive-control functioning and cognitive-affective balance in maltreated children, Developmental Psychology, 25, 382393.

Rogosch, F.A., Cicchetti, D., \& Aber, J.L. (1995). The role of child maltreatment in early deviations in cognitive and affective processing abilities and later peer relationship problems. Dovelopmental and Psychopathology, 7, 591-609.

Santostetano, S. (1978). A biodevelopnental approach to clinical child psychology: Cognitive contols and cognitive control therapy. New York: Wiley. 
Santostefano, S. (1985). Cognitive control therapy with children and adolescents. Oxford: Pergamon Press.

Santostefano, S. (1986). Cognitive controls, metaphors and contexts: An approach to cognition and emotion. In D. Bearision \& $\mathrm{H}$. Zimiles (Eds.), Thenght and emonion (pp. 175-210). Hillsdale, NJ: Estbaum.

Santostefano, S. (1988). The Cognitive Control Battery. Los Angcles, CA: Western Psychological Services,

Santostefano, S. (1991). Cognitive style as process coordinating outer space with inmer self: Lessons from the past. In S. Wapner \& J. Demick (Eds.), Field dependence-independence: Cognitive style across the life span (pp. 269-288). Hillsdale, NJ: Erlbaum.

Santostefano, S. (1992a). The Leveling-Sharpening Friends, Shootout, and Trama Tests: Manual of instructions and scoring. Wellesley, MA: ICAD

Santostefano, S. (1992b). Life Stressor Interview: Manual of instructions and scoring. Wellesley, MA: ICAD.

Santostcfano, S. (1995). Embodied meanings, cognition, and emotion: Probing how three are one. In D. Cicchetti \& S.L. Toth (Eds.), Rochesfer Sympoxium on developmental psychopathology. Vol. 6: Emotion, cognition and representation. (pp. 59-132). Rochester, NY: University of Rochester Press.

Santostefano, S. (1998). A handbook of integrative psychotherapies for children and adolescents. Northvale, NJ: Jason Aronson.

Santostefano, S., \& Moncata. S. (1989). A psychoanalytic view of cognition within personality: Cognitive dysfunction and educating troublod youth. Residential Treament for Children and Youth, 6, 41-62.

Santostefano, S. \& Paley, E. (1964) Development of cognitive controls in children. Child Development, 35, 939-949.

Santostefano, S. \& Ricder, C. (1984). Cognitive controls and aggression in children; The concept of cognitive-affective balance. Joumal of Consulting and Clinical Psychology, 52, 46-56.

Shapiro, I.F. (1972). Cognitive controls and adaptation in children. Unpublished doctoral dissenation, Boston College, Boston, MA.

Van der Kolk, B.A., \& Ducey, C.P. (1989). The psychological processing of traumatic experience: Rorschach patterns in PTSD. Joumal of Tramaic Stress, 2, 259-274.

Wertlieb, D. L. (1979). Cognitive organization, regulations of aggression and leaming disorders in boys. Unpublished doctoral dissertation, Boston University, Boston, MA,

White, S.H. (1991). The child as agent: Issues of cognitive style and personal design in human development. In S. Wapner \& I. Demick (Eds.), Field dependence-independence: Cognitive sryle across the life span (pp. 7-24). Hillsdale, NJ: Erlbaum.

Wolitsky, D.L.. \& Wachtel, P.L. (1973). Personality and perception. In B.B. Wolman (Ed.), Handbook of general psychology (pp. 826-857). Englewood Cliffs, NJ: Prentice Hall.

Received September 20, 1999

Revision received April 27, 2000

Accepted June 2, 2000 